\title{
AS CRÔNICAS COLONIAIS NO ENSINO DE HISTÓRIA DA AMÉRICA
}

\section{COLONIAL CHRONICLES AND THE TEACHING OF AMERICAN HISTORY}

Susane Rodrigues de Oliveira ${ }^{1}$

\begin{abstract}
RESUMO: Este artigo discute os limites e possibilidades no uso das crônicas coloniais como materiais didáticos para o ensino de história da América na educação básica. Trata-se especialmente de crônicas em língua espanhola, escritas nos séculos XVI e XVII, sobre a natureza, os povos indígenas e o processo de conquista e colonização européia da América. Com o objetivo de contribuir na educação escolar para a cidadania crítica, as orientações pedagógicas traçadas neste artigo se baseiam no estudo das representações sociais, das condições de produção dos discursos e nas propostas dos PCNs para o trabalho com eixos temáticos e documentos históricos em sala de aula.
\end{abstract}

Palavras-chave: Representações. Crônicas. Indígenas. Materiais didáticos.

\begin{abstract}
This article discusses the limits and possibilities in the use of colonial chronicles as teaching materials for teaching American history in elementary education. This is especially chronic in Spanish, written in the sixteenth and seventeenth centuries, on nature, indigenous people and the process of conquest and colonization of America. With the objective to contribute in school education for critical citizenship, pedagogical guidelines outlined in this article are based on the study of social representations, the conditions of discourse production of PCNs and proposals for working with themes and historical documents in room class.
\end{abstract}

Keywords: Representations. Chronicles. Indigenous. Teaching Materials.

1 Doutora em História pela Universidade de Brasília e docente adjunto nesta mesma instituição na área de Teoria e Metodologia do Ensino de História. susanero@gmail.com 


\section{Introdução}

Este artigo $^{2}$ discute os limites e possibilidades no uso das crônicas coloniais como materiais didáticos para o ensino de história da América na educação básica. Trata-se especialmente de crônicas em língua espanhola, escritas nos séculos XVI e XVII, sobre a natureza, os povos indígenas e o processo de conquista e colonização européia da América. Com o intuito de contribuir na educação escolar para a cidadania crítica, traçamos aqui algumas orientações pedagógicas para a abordagem das crônicas em sala de aula, tendo em vista a problematização das representações históricas construídas sobre os povos indígenas e a conquista/colonização hispânica da América. Estas orientações se fundamentam no estudo das Representações Sociais, das condições de produção dos discursos e nas propostas dos Parâmetros Curriculares Nacionais (PCNs) para o trabalho com eixos temáticos e documentos históricos em sala de aula.

A partir do século XII na Espanha, a crônica esteve estreitamente ligada à instituição monárquica e à imagem dos reis e da nobreza, tornando-se modelo de escrita preponderante para se registrar e celebrar os "grandes feitos" históricos das monarquias (OLIVEIRA, 2002, p. 8).

A crônica era uma "lista" cronologicamente organizada acerca dos acontecimentos que se desejavam conservar na memória e ressaltar como exemplos a serem seguidos. Como um registro literário de natureza descritiva e pedagógica, ela constitui, então, uma rememorização organizada acerca dos "grandes feitos" dos monarcas e das monarquias, bastante proliferada nos períodos que se seguiram da Idade Média à conquista da América (Idem, p. 11).

Nos séculos XV e XVI as crônicas penetram na América por mandato real, visto que as ordenações hispânicas sobre as conquistas e descobrimentos prescreviam aos que fossem às costas americanas com o objetivo de explorar a terra, levar um "Veedor" -, geralmente um

\footnotetext{
2 A pesquisa apresentada neste artigo faz parte das atividades do projeto "Produção de materiais didáticos para o ensino de História da América indígena e da Conquista Espanhola", em desenvolvimento no Laboratório de Ensino de História da UnB, que conta com o apoio da FINATEC, através do Edital 04/2009.
} 
funcionário da Coroa, soldado, capitão ou membro do clero que fosse letrado, - para atuar como escrivão responsável pela descrição da terra, de suas riquezas e dos usos e costumes de seus habitantes (MIGNOLO, 1998). A grandiosidade, a diversidade, a riqueza e a complexa organização dos povos Astecas e Incas captaram especialmente a atenção dos espanhóis que,

\begin{abstract}
Embora impressionados e mesmo incomodados ante $\mathrm{o}$ inusitado, tinham urgência de um (re)conhecimento dessa humanidade estranha e desconhecida. A surpreendente diferença confrontada criava a necessidade de ser reconhecida, ou melhor, incorporada, para atenuar seu conteúdo perturbador, desconhecido, para a Espanha, de forma a assegurar a esta seu poder de nomeação, sua posição de dominação nos territórios americanos conquistados (OLIVEIRA, 2008, p. 196).
\end{abstract}

No entanto, a repugnância em pensar a diferença confrontada na América revela-se nas crônicas, que são finalmente a vontade discursiva de ordenar o mundo em espaços simbólicos já conhecidos, de estabelecer um regime de verdade sobre o Outro, especialmente os ameríndios, ao nomeálos como bárbaros, demoníacos, selvagens e tiranos, já que não eram cristãos, brancos e nem "civilizados". Deste modo, as representações ${ }^{3}$ dos indígenas veiculadas nas crônicas revelam um conjunto de saberes assentados em paradigmas europeus.

As crônicas puderam mobilizar forças no processo de assujeitamento dos indígenas e responder "pela instauração de hierarquias, lugares sociais, desigualdades e diferenças entre índios e europeus, entre homens e mulheres, entre os indivíduos dos dois mundos que se encontram e se confrontam" (OLIVEIRA, 2002, p. 24). Neste sentido, a utilização indiscriminada das crônicas e demais documentos coloniais na abordagem da história indígena pré-colombiana e da colonização européia da América pode incorrer na reprodução do olhar eurocêntrico dos cronistas que estiveram a cargo da exaltação dos feitos europeus na conquista da América. Esse tipo de história acabou por silenciar, inferiorizar e/ou negar

\footnotetext{
3 Entendemos as Representações Sociais como "Forma[s] de conhecimento[s], socialmente elaborada[s] e partilhada[s], com um objetivo prático, e que contribui[em] para a construção de uma realidade comum a um conjunto social" (JODELET, 2001, p. 22).
} 
os conhecimentos e práticas dos ameríndios; negou-Ihes, enfim, o direito de ter especificidades e particulares históricas e culturais reiterando uma série de conceitos globalizantes e essencialistas a respeito das identidades e diferenças.

As crônicas produzidas por espanhóis envolvidos no processo de colonização e evangelização da América, e também por alguns índios e mestiços cristianizados nos séculos XVI e XVII, constituem as principais fontes de pesquisa utilizadas pelos historiadores no estudo da América précolombiana e colonial. Tudo isso se deve à escassez de fontes escritas pelos próprios Incas, Astecas, Maias e outros povos indígenas em tempos précolombianos ou coloniais. Como bem observou Natalino (2004, p. 177), isto pode estar relacionado ao "papel preponderante que era desempenhado pelas narrativas orais e por formas de registro muito distintas das que tradicionalmente reconhecemos como tais, como por exemplo os ceques, [...] os quipus, os pallares ou os tocapus".

No entanto, a utilização das crônicas como fontes de pesquisa ainda suscitam uma série de indagações e desafios. Franklin Pease (1994, p. 122) criticou a utilização indiscriminada das crônicas como fontes de pesquisa, mas destacou a importância de sua utilização para a compreensão das categorias que proporcionaram a apreensão das antigas sociedades andinas. Mesmo reconhecendo os limites das crônicas para tratar destas sociedades, bem como de todo e qualquer discurso sobre o passado, alguns pesquisadores não abandonaram essas narrativas como fontes de pesquisa, mas passaram a utilizá-las em sua dimensão de documentos construídos e não reflexos do real. Além disso, os pesquisadores reconheceram que apesar das crônicas serem escritas sob o ponto de vista espanhol, apresentam alguns indícios para a percepção da materialidade indígena.

Os indígenas foram historicamente construídos nas crônicas por representações marcadas pelos vieses colonialistas e seu corolário de apagamentos e exclusões; por isso eles não podem ser reduzidos a essas representações. Como bem atenta Jovchelovith (2002, p. 78), "Precisamos manter a distinção entre a representação e o objeto, porque é na pluralidade dos processos representacionais que reside a possibilidade de 
manter o objeto aberto para as tentativas constantes de (re) significação que lhe são dirigidas". É nessa perspectiva que propomos neste artigo uma abordagem das crônicas coloniais como materiais didáticos nas aulas de história, com o objetivo de problematizar as representações e discutir a condições de produção do conhecimento sobre a América e os povos indígenas nas crônicas coloniais; ou seja, de estudar as condições de produção ${ }^{4}$ das representações dos povos indígenas no cenário da conquista da América, - a historicidade de suas elaborações, - buscando romper com a universalização e naturalização das imagens dos indígenas e europeus na história.

\section{Possibilidades e Limites no Uso das Crônicas Coloniais em Sala De Aula}

Baseando-se ainda em tradição historiográfica eurocêntrica os conteúdos de boa parte dos livros didáticos escolares continuam reproduzindo fragmentos de fontes históricas, especialmente de crônicas coloniais, sem a mínima problematização e crítica, especialmente quando se trata das sociedades ameríndias antes de 1492 ou de suas resistências ao processo de conquista/colonização européia. No livro didático História das cavernas ao Terceiro Milênio ${ }^{5}$, produzido para o Ensino Médio, identificamos dois fragmentos de crônicas coloniais sobre os Incas, no capítulo que trata das culturas indígenas do continente americano antes da chegada dos europeus. Estes fragmentos das crônicas do soldado espanhol Cieza de León e do mestiço Garcilaso de La Vega aparecem como textos complementares, sem nenhuma referência ou questionamento às suas condições de produção. Deste modo, as crônicas parecem ganhar um status de verdade, como retratos fiéis do passado ao veicular uma espécie de história pronta e acabada. Esta forma de abordagem das crônicas parece inibir a capacidade

${ }^{4}$ Condições de produção implicam "o que é material (a língua sujeita a equívoco e a historicidade), o que é institucional (a formação social, em sua ordem) e o mecanismo imaginário. Esse mecanismo produz imagens dos sujeitos, assim como do objeto do discurso, dentro de uma conjuntura sócio-histórica" (ORLANDI, 2003, p. 40).

${ }^{5}$ Este livro é de autoria de Patrícia Ramos Braick \& Myriam Becho Mota, lançado pela editora Moderna em 2002. 
interpretativa dos estudantes, marcando-os como sujeitos passivos diante do conhecimento.

Alguns estudiosos ${ }^{6}$ também observaram que os livros didáticos de história ainda permanecem informados por um conjunto de saberes eurocêntricos que constroem uma verdade sobre os povos indígenas e a América colonial, ao enunciar e fazer circular representações preconceituosas a respeito do passado e identidades indígenas. Estes livros também possuem o poder de reiterar representações que funcionam como matrizes e efeitos de práticas e concepções que criam identidades, diferenças, desigualdades, hierarquias e exclusões sociais.

Tanto a história como os documentos do passado constituem veículos de representações que produziram e produzem efeitos de sentidos a serem compreendidos nas condições em que apareceram e nas de hoje. Então, não se trata de, a partir da história da época, ler as crônicas como a sua ilustração e acrescentar detalhes. $\mathrm{Na}$ maior parte das vezes os/as professores/as utilizam diferentes fontes apenas para ilustrar os temas tratadas nas aulas de história, sem problematizar as suas condições de produção. Nesse sentido é fundamental que o/a professor/a de história adote procedimentos metodológicos que trate as crônicas como objeto de pesquisa histórica e como voz de sujeitos históricos, enfim como discursos carregados de sentidos, valores e representações do passado que precisam ser problematizados. Este trabalho com as crônicas possibilita a percepção de diferentes "modos de ver" e significar o passado, além da compreensão da historicidade das interpretações e das relações da linguagem com a cultura e o poder. Neste caminho abre-se possibilidade para que os estudantes também possam interpretar o passado e reconhecer $a$ historicidade de suas próprias representações acerca dos indígenas e a conquista da América.

\footnotetext{
${ }^{6}$ Cf. FERNANDES \& MORAIS, 2004. Ver também KOLING, Paulo José. O ensino de História da América na educação básica: reflexões a partir de livros didáticos e obras utilizadas em escolas públicas no Oeste do Paraná. In: Anais Eletrônicos do VIII Encontro Internacional da ANPHLAC. Vitória, 2008.
} 
Vivemos numa sociedade imagética, caracterizada pela comunicação de massa, onde vigora a forças das representações históricas produzidas e veiculadas pela mídia, impondo à escola o desafio de estimular os estudantes na interpretação crítica destas representações, para o estabelecimento de uma atitude ativa e dialógica diante da televisão e do conhecimento histórico (ZAMBONI, 1998). As idéias dos estudantes, da mesma forma que as dos cronistas, historiadores e aquelas que circulam na mídia, não devem, portanto, ser tomadas como verdadeiras ou erradas, mas como objetos de estudo, de problematização.

Como bem atenta os PCNs,

É preciso considerar, ainda, o fato de que as primeiras impressões de quem lê um texto ou observa uma gravura estão impregnadas de representações, idéias, valores e informações difundidas na sociedade. É a análise do documento nos seus detalhes, as confrontações com outras fontes, a sua inserção nos contextos de época, os questionamentos quanto às suas contradições e coerências internas etc., que irão permitir ao estudante conquistar procedimentos e atitudes de pensar/refletir historicamente e construir conhecimentos de natureza científica (BRASIL, 1998, p. 86-7).

De acordo com Schmidt e Cainelli (2004, p. 52), no ensino de História, problematizar é construir um diálogo entre o presente e o passado, e não reproduzir conhecimentos neutros e acabados sobre os fatos passados, tendo também como referência o cotidiano dos estudantes e do/a professor/a. Os saberes históricos que circulam no nosso cotidiano devem ser o ponto de partida para o planejamento e organização da aprendizagem. Nesta perspectiva, os estudantes podem ser indagados sobre suas representações acerca do passado indígena na América. As questões problematizadoras devem partir da cultura experiencial dos estudantes, de representações que eles possuem sobre os acontecimentos do passado. Este caminho propicia reflexões sobre a relação presentepassado e cria também situações didáticas para que os estudantes conheçam e dominem procedimentos de como interrogar obras humanas do seu tempo e de outras épocas. 
O uso das crônicas como materiais didáticos requer um trabalho inicial de seleção de fragmentos curtos, de acordo com a faixa etária e a capacidade de motivação dos estudantes para leitura e análise destes documentos em sala de aula. A partir disso, com o propósito didático o/a professor/a pode solicitar aos estudantes as suas primeiras impressões sobre as crônicas, instigá-los no questionamento e confrontar com informações divergentes.

Devemos ressaltar que a maioria das crônicas está publicada em língua espanhola, o que requer um trabalho de tradução que pode ser feito na própria escola em atividade interdisciplinar. Esta possibilidade advém da Lei 11.161, sancionada em 2005, que estabelece a obrigatoriedade do ensino de língua espanhola para o Ensino Médio em todo o país a partir de 2010; no ensino fundamental de $6^{\circ}$ a $9^{\circ}$ ano a oferta deste ensino será facultativa.

O primeiro passo na abordagem das crônicas consiste, portanto, na leitura e decomposição dos seus elementos. Os estudantes podem identificar palavras desconhecidas e pesquisar os seus significados; além disso, podem identificar os personagens e/ou acontecimentos mencionados no texto e realizar uma pesquisa sobre eles. Em seguida podemos colocar algumas questões: que tipo documento é esse? Quem o construiu (elaborou)? O que nos diz? Como o diz? Onde? Quem o fez? Com que finalidades? Em nome de quem? Para quem? Com que propósito? Estas são perguntas básicas que podem orientar as atividades com outros documentos históricos em sala de aula. É necessário desestruturar o documento para apreender as suas condições de produção. Nesta perspectiva destacamos as contribuições de Michel Foucault - sobre as perguntas dirigidas ao documento: quem disse isso? Onde? Quando? E por quê? Para quem?

Neste caminho destacamos ainda o movimento teórico e metodológico da História em desnaturalizar as fontes, ou seja, em refletir que os documentos, sejam eles escritos, iconográficos ou orais, não expressam um significado central, coerente, comunal, não são transparentes e nem inocentes, foram produzidos segundo determinados 
interesses e estratégias, assim como implicam uma desigualdade na sua apropriação. Como bem atenta Chartier (1998), mais do que perguntar o que um documento significa, os historiadores hoje se perguntam como ele funciona. A produção de significados e o funcionamento das crônicas podem estar transversalisados pelas questões de classe, gênero, etnia, religião, economia, política, diferenças, desigualdades, dentre outras que merecem ser problematizadas em sala de aula.

As indagações iniciais sobre as crônicas possibilitam um momento de apresentação do documento em sala de aula. Em seguida partimos para o momento de sua explicação, onde as crônicas devem ser situadas no tempo e espaço de sua produção e relacionadas com os acontecimentos apresentados pelo/a professor/a em sala de aula, aos que aparecem no livro didático ou em outras fontes, como a internet, revistas, jornais, televisão ou cinema. Este trabalho permite ainda problematizar as questões iniciais sobre a autoria, a natureza do texto e as idéias apresentadas. Com atenção o/a professor/a pode solicitar ainda que os estudantes identifiquem valores, sentidos, fatos, conceitos, estética e representações sociais na leitura atenta das crônicas. No caminho do questionamento das imagens e valores destacados nas crônicas, o/a professor/a precisa ter uma bagagem de conhecimento histórico para orientar a historicização dos aspectos destacados. Neste sentido, impõe-se a formação do/a professor/apesquisador/a que saiba confrontar/selecionar a historiografia e os documentos mais adequados ao processo de ensino-aprendizagem. Esta postura é importante para que o/a professor/a/a saiba conduzir a problematização das crônicas e do próprio saber histórico em sala de aula, para que tanto ele como os estudantes não se tornem prisioneiros das concepções e valores veiculados nas crônicas. As crônicas, portanto, não podem ser utilizadas apenas como exemplos ilustrativos da história, mas sim como discursos carregados de sentidos e valores, imagens e representações, cujas condições de produção necessitam ser apreendidas e interpretadas. Desse modo, podemos também contribuir na formação do estudante como sujeito crítico e produtor de conhecimento histórico.

Por fim, os estudantes podem estabelecer relações entre o conteúdo das crônicas e dos saberes históricos que circulam no presente. Além das 
atividades de leitura, debates, comparações e pesquisas, é possível ainda utilizar as crônicas na produção de textos para que os estudantes expressem também suas interpretações de forma escrita. Nesta atividade os estudantes podem expressar suas concepções acerca dos temas tratados nas crônicas e, especialmente, questionar as representações históricas dos povos indígenas e as nossas relações com estes povos no presente. Ao reorganizar o seu conhecimento ou identificar semelhanças e diferenças entre o que já sabia e o novo conteúdo apreendido, revela-se o papel ativo do aluno no próprio processo de ensino-aprendizagem. Ao construir narrativas sobre os temas abordados nas crônicas os estudantes também produzem sentidos e significados para o passado. Estas narrativas permitem ainda ao/à professor/a uma percepção das representações históricas construídas e assimiladas pelos estudantes durante o processo de aprendizagem.

\section{Eixos Temáticos e Recorte nas Crônicas}

É preciso escolher o momento adequado para trabalhar com as crônicas coloniais em sala de aula, definir claramente os objetivos didáticos a serem atingidos e considerar a especificidade da temática histórica a ser estudada. Foi observando os eixos temáticos propostos pelos PCNs de História para o terceiro e quarto ciclos do ensino de fundamental (BRASIL, 1998), que vislumbramos algumas possibilidades especialmente para o trabalho com as crônicas escritas sobre os Incas e a conquista hispânica do Peru. Para o terceiro ciclo do ensino fundamental, os PCNs propõe o eixo temático "História das relações sociais, da cultura e do trabalho", já para o quarto ciclo propõe "História das representações e das relações de poder". Assim se justifica estes recortes históricos e didáticos:

Os eixos temáticos e subtemas que deles derivam procuram dar conta de duas grandes questões históricas tão clássicas quanto atuais. A primeira refere-se aos contatos culturais, inter-relações e confrontos entre grupos, classes, povos, culturas e nações. As lutas sociais de grupos e de classes, que 
reivindicam respeito às diferenças e igualdades, e as lutas de culturas e de etnias na defesa de seus territórios e de suas identidades são problemas cruciais do mundo de hoje. São importantes temas de estudo, na medida em que buscam a compreensão da diversidade de modos de vida, de culturas e de representações internas das sociedades e das organizações sociais. São historicamente relevantes por possibilitarem estudos sobre trocas, intercâmbios e confrontos que contribuem para as transformações e as permanências históricas. Favorecem a percepção dos conflitos geradores de situações de dominação, discriminação, luta, igualdade e desigualdade (BRASIL, 1998, p. 47).

O eixo temático para o terceiro ciclo se desdobra ainda em dois subtemas: "as relações sociais e a natureza" e "as relações de trabalho". Dentro destes subtemas os conteúdos de História do Brasil, História da América, da Europa, da África e do Oriente estão agrupados separadamente. No que se refere à História da América pré-colombiana e colonial identificamos nos PCNs os seguintes temas:

[...] relações entre a sociedade, a cultura e a natureza na História dos povos americanos na Antiguidade e entre seus descendentes hoje: [...]

- a natureza nos mitos, nos ritos e na religião; ciclos naturais e calendários;

- uso da água, seu represamento, irrigação e adubos; usos da terra; adaptação cultural à diversidade natural;

- alimentação e recursos naturais nas habitações, vestimentas e utensílios;

- natureza nas cidades; meios de transporte e interferências na natureza na implantação de infra-estruturas; paisagens naturais, rurais e urbanas;

- natureza e povos da América na visão dos europeus; exploração econômica de recursos naturais pelos colonizadores europeus (BRASIL, 1998, p. 58-59).

Para o quarto ciclo do ensino fundamental os PCNs propõe o eixo temático "História das representações e das relações de poder", que se desdobra em dois subtemas: "Nações, povos, lutas, guerras e revoluções" e "Cidadania e cultura no mundo contemporâneo". Dentre os conteúdos listados para o trabalho com o subtema "Nações, povos, lutas, guerras e revoluções" identificamos alguns temas de História da América que podem ser trabalhados a partir das crônicas: 
- administração das colônias espanholas, subjugação das etnias e das culturas nativas [...];

- guerras e expansão do império Incas e do império Asteca, confronto entre europeus e populações nativas da América espanhola [...] (BRASIL, 1998 p. 70).

$\mathrm{Na}$ abordagem dos eixos temáticos para o terceiro ciclo podemos sugerir o trabalho com crônicas que tratam dos Incas e que descrevem suas habitações, alimentação, usos da água, calendários, técnicas de irrigação, cidades, organização política/social, educação, organização do trabalho, vestimentas, utensílios e as paisagens naturais em que os Incas viviam.

A obra do frei mercedário Martin de Murúa [1590] - História das origens e genealogia real dos Incas -, ainda pouco conhecida, apresenta uma descrição físico-geográfica e urbana do Peru na época da chegada dos espanhóis. A segunda parte da obra trata do governo, administração, justiça e das guerras movidas pelos Incas. Além disso, dedica muitas páginas ao entendimento dos mitos, festas, calendários, rituais e religião dos Incas, onde é possível perceber indícios das relações que os Incas estabeleceram com a natureza.

As crônicas coloniais permitem também uma abordagem da visão européia sobre a natureza americana nos séculos XVI e XVII. No processo de colonização e exploração econômica das terras americanas as informações sobre a natureza eram mais úteis e urgentes. Não por acaso as crônicas apresentavam em sua estrutura uma primeira parte dedicada exclusivamente à descrição físico-geográfica da terra.

A Historia natural y moral de las Indias, do cronista e jesuíta espanhol Jose de Acosta [1589], é bastante reveladora desse olhar europeu sobre a natureza americana, especialmente na primeira parte de sua narrativa onde se dedica a uma descrição das plantas e animais encontrados no "Novo Mundo". Sua crônica foi dividida em dois blocos, reproduzindo, significativamente, a dicotomia natureza/cultura configuradora do imaginário europeu a respeito do cosmos: a primeira parte, consagrada à história natural, "ao céu e à habitação das Índias em geral", com abordagem dos três elementos (terra, água e ar) e dos compostos (metais, plantas e animais) - , trata da natureza, onde, segundo 
Acosta, não existe o livre arbítrio, pois pertence à ordem natural das coisas; já a segunda parte, dedicada a história moral faz referências ao mundo humano e suas criações. A sua História natural busca demonstrar que a América era feita da mesma matéria que as outras partes do mundo conhecidas pelos europeus no século XVI, e como seus habitantes participavam da mesma natureza dos demais. O mundo, com efeito, deixava de ser pensado dentro dos limites tradicionais demarcados pelo Oceano, abraçando a totalidade do globo terráqueo. A segunda parte da obra, dedicada à História moral, trata especialmente da vida espiritual dos povos que se pretendia conquistar na América. O desejo do cronista em escrever uma história dos costumes, leis e governos dos Astecas e Incas, encontrava justificativa precisamente na concepção providencialista do mundo, de que a providencia divina poderia ajudar a lograr a salvação eterna dos índios. Não por acaso nesta narrativa o cronista associa as religiosidades Inca e Asteca ao demônio e à maldade, às práticas pagãs que na ótica cristã e européia do século XVI deveriam ser combatidas no caminho da salvação espiritual.

O cronista espanhol Sarmiento de Gamboa, empossado no cargo de cosmógrafo geral dos reinos do Peru, por volta de 1571, tornou-se responsável pela demarcação destas terras. Durante o exercício desse cargo escreveu a Historia General Ilamada Indica, seguindo também os padrões das crônicas de sua época, onde apresenta uma primeira parte dedicada à História natural - com a descrição geográfica das terras hispano-americanas - dando ênfase às suas utilidades para prover o governo, estabelecer bispados, dar concessões de povoamento e descobrimentos aos espanhóis. A segunda parte de sua obra, intitulada La Historia de los Incas trata do governo dos Incas sobre Andes. Já na terceira parte trata do "tempo dos espanhóis", destacando os seus feitos notáveis nos descobrimentos e povoamento do Peru até o ano de 1572. Como funcionário da Coroa e do vice-rei Toledo no Peru procurava em seus textos dar legitimidade à conquista espanhola, buscando enfatizar o caráter bélico, as guerras, as mentiras e as crueldades dos Incas, imprimindo imagens que desclassificavam o poder e domínio dos Incas sobre aquelas terras. Dessa forma, ele é um dos artífices do chamado "mito da usurpação", construindo 
uma imagem do governo e da ordem incaica como ilegítima e usurpadora. Um saber, portanto, que foi instituído/instituidor pelas/das práticas da conquista espanhola nos Andes.

Já a crônica de Garcilaso de La Vega, Comentários Reales de los Incas $^{7}$ [1609], é uma das mais utilizadas quando se trata da história dos Incas e da conquista hispânica do Peru. Este cronista trata de temas como a origem, expansão, organização política, alimentação, riquezas, religião, governantes, festas, trabalho e relações sociais, étnicas e de gênero no governo dos Incas. Descreve ainda as cidades, fortalezas, estradas, o uso da terra, o cultivo do milho e outros vegetais no mundo incaico. Muitos autores conferem credibilidade ao seu trabalho, por se tratar de um mestiço, filho de uma princesa Inca com um capitão espanhol. No entanto, devemos notar que este cronista fez associações da cultura Inca e à cristã européia, exaltando ao mesmo tempo o colonialismo e a dominação européia da América.

As crônicas contêm uma infinidade de situações que nos permitem trabalhar com diferentes representações sobre um mesmo objeto. Um deles é o da representação do governo dos Incas sobre os Andes. Garcilaso de La Vega esteve mais interessado em revelar uma imagem dos Incas como dóceis, civilizados, benfeitores e de boa razão, ao contrário de outros cronistas, - como Sarmiento de Gamboa, e indiretamente Guaman Poma de Ayala, - que estiveram a cargo da Coroa espanhola, comprometidos com a construção de uma imagem negativa dos Incas como cruéis, tirânicos, bárbaros e idólatras, a fim de legitimar os justos títulos da Espanha sobre as terras do Peru. Na visão de Garcilaso, os Incas constituíram instrumentos da divina providência para livrar as populações andinas do pecado e da idolatria, preparando-as para o recebimento do evangelho com a chegada dos colonizadores espanhóis.

Para a abordagem das guerras e expansão do "império" Inca sugerimos ainda um trabalho de comparação das visões apresentadas pelos cronistas Sarmiento de Gamboa e Garcilaso de La Vega. Sarmiento de

7 Uma versão bastante desta obra se encontra em língua portuguesa, intitulada O Universo Incaico (1992).

História \& Ensino, Londrina, v. 17, n. 2, p. 235-256, jul./dez. 2011 
Gamboa apresenta uma visão negativa das origens e do processo de expansão do "império" Inca, já que retrata os Incas como sujeitos tirânicos, bárbaros e cruéis que usurparam a terra e subjugaram injustamente as etnias que habitavam o Peru. Este ponto de vista é bastante revelador do desejo de construir uma imagem negativa do governo dos Incas a fim de justificar a intervenção e o governo dos espanhóis na América. Já Garcilaso de la Vega, traça uma imagem dos Incas como sujeitos pacíficos e responsáveis pela "civilização" e organização dos Andes que ganham méritos por prepararem as populações andinas para receberem os princípios da colonização e evangelização hispânica. O seu discurso aproxima os Incas dos espanhóis, na medida em que faz associações dos valores incaicos com os da cristandade, uma tentativa de igualar os Incas à nobreza hispânica. $\mathrm{Na}$ análise destas duas crônicas é importante levar em conta o "lugar de fala" dos cronistas. Neste sentido, os/as professores/as podem pedir aos estudantes que façam uma pesquisa sobre a vida e a obra destes cronistas, para o entendimento das representações e dos valores que circulam em seus relatos. Como bem sugere os PCNs,

\footnotetext{
É possível pesquisar informações sobre o documento em fontes externas (autoria, contexto da obra, estilo etc.) e confrontar eventos históricos identificados na fonte estudada a eventos de outras épocas, quanto a semelhanças e/ou diferenças e relações de continuidade e/ou descontinuidade. Quando o professor considerar necessário, pode ser feita a pesquisa da trajetória histórica de preservação, conservação e difusão do documento. (BRASIL, 1998, p. 86-87).
}

Este tipo de trabalho permite que o estudante perceba o processo de construção do conhecimento, ou seja, as condições de produção destas narrativas. Deste modo é possível empreender um trabalho de desnaturalização do documento, ao seja, revelar o seu caráter histórico, suas regras, valores e mecanismos de funcionamento.

$\mathrm{Na}$ abordagem do tema "administração das colônias" e "subjugação das etnias e das culturas nativas", trechos da crônica do espanhol Juan de Betanzos [1551] possibilitam a apreensão da visão européia da conquista, especialmente em suas descrições dos episódios da conquista do Peru, dos confrontos bélicos e das relações que os espanhóis estabeleceram com os Incas. 
Para o entendimento do ponto de vista indígena da conquista e colonização dos Andes, a crônica do indígena cristianizado Felipe Guaman Poma de Ayla (Nueva Corónica y Buen Gobierno [1615/1616]) é também bastante reveladora, já que se apresenta como um discurso de denúncia das atrocidades cometidas pelos espanhóis contra os índios na tentativa de colonização do Peru. No entanto, devemos ficar atentos ao fato de que Guaman Poma atuou como ajudante do extirpador das idolatrias Cristóbal de Albornoz, entre os anos 1569 e 1571, na tarefa de conhecer os ritos e simbologia da religião andina no tempo dos Incas. Na mesma linha de construção de Sarmiento de Gamboa, Guaman Poma busca argumentos para desprestigiar os Incas, buscando legitimar os justos títulos da conquista espanhola sobre os Andes. Ao enunciar o seu discurso na forma de crônica, Guaman Poma segue as normas, estrutura e conceitos que moldavam este gênero literário reconhecido e autorizado para se falar da América e seus habitantes no século XVI (OLIVEIRA, 2006). O livro A conquista da América latina vista pelos índios, de autoria de León-Portilha (1987), apresenta em sua terceira parte, dedicada à memória quéchua da conquista, alguns fragmentos da Nueva Corónica y Buen Gobierno, traduzidos para o português. Estas narrativas são reveladoras dos interesses colonialistas, dos conflitos, relações de poder e resistências dos Incas à dominação espanhola.

Já a crônica do frei dominicano Bartolomé de Las Casas [1474-1566] também é bastante reveladora dos confrontos e relações de poder entre espanhóis e indígenas nos primeiros anos da conquista. A obra Brevíssima relação da destruição das Índias Ocidentais, lançada em 1552, aparece entre as mais citadas ${ }^{8}$ nos livros didáticos, perpetuando uma representação dos indígenas apenas como vítimas da violência hispânica, incapazes de resistência.

8 Cf. Projeto Araribá: História 7. Ensino Fundamental. Obra de autoria coletiva concebida, desenvolvida e produzida pela Editora Moderna em 2007. 
[...] Na ilha Espanhola que foi a primeira, como se disse, a que chegaram os espanhóis, começaram as grandes matanças e perdas de gente, tendo os espanhóis começado a tomar as mulheres e filhos dos índios para deles servir-se e usar mal e a comer seus víveres adquiridos por seus suores e trabalhos, não se contentando com o que os índios de bom grado thes davam, cada qual segundo sua faculdade, a qual é sempre pequena porque estão acostumados a não ter de provisão mais do que necessitam e que obtêm com pouco trabalho. E o que pode bastar durante um mês para três lares de dez pessoas, um espanhol o come ou destrói num só dia. Depois de muitos outros abusos, violências e tormentos a que os submetiam, os índios começaram a perceber que esses homens não podiam ter descido do céu. Alguns escondiam suas carnes, outros suas mulheres e seus filhos e outros fugiam para as montanhas a fim de se afastar dessa Nação. Os espanhóis Ihes davam bofetadas, socos e bastonadas e se ingeriam em sua vida até deitar a mão sobre os senhores das cidades. E tudo chegou a tão grande temeridade e dissolução que um capitão espanhol teve a ousadia de violar pela força a mulher do maior rei e senhor de toda esta ilha. Cousa essa que desde esse tempo deu motivo a que os índios procurassem meios para lançar os espanhóis fora de suas terras e se pusessem em armas: mas que armas? São tão fracos e de tão poucos expedientes que suas guerras não são mais que brinquedos de crianças que jogassem com canas ou instrumentos frágeis. Os espanhóis, com seus cavalos, suas espadas e lanças começaram a praticar crueldades estranhas; entravam nas vilas, burgos e aldeias, não poupando nem as crianças e os homens velhos, nem as mulheres grávidas e parturientes e Ihes abriam o ventre e as faziam em pedaços como se estivessem golpeando cordeiros fechados em seu redil. [...] Arrancavam os filhos dos seios da mãe e lhes esfregavam a cabeça contra os rochedos enquanto que outros os lançavam à água dos córregos rindo e caçoando, e quando estavam na água gritavam: move-te, corpo de tal?! Outros, mais furiosos, passavam mães e filhos a fio de espada. Faziam certas forcas longas e baixas, de modo que os pés tocavam quase a terra, um para cada treze, em honra e reverência de Nosso Senhor e de seus doze Apóstolos (como diziam) e deitando-Ihes fogo, queimavam vivos todos os que ali estavam presos. [...] Dessa maneira procediam comumente com os nobres e os senhores; faziam certos gradis sobre garfos com um pequeno fogo por baixo a fim de que, lentamente, dando gritos e em tormentos infinitos, rendessem o espírito ao Criador. [...] Eu vi as cousas acima referidas e um número infinito de outras; e pois que os que podiam fugir ocultavamse nas montanhas a fim de escapar a esses homens desumanos, despojados de qualquer piedade, ensinavam cães a fazer em pedaços um índio à primeira vista. Esses cães faziam grandes matanças e como por vezes os índios matavam algum, os espanhóis fizeram uma lei entre eles, segundo a qual por um espanhol morto faziam morrer cem índios (LAS CASAS, 2001, 33-35). 
$\mathrm{Na}$ abordagem deste fragmento podemos problematizar a representação dos índios como vítimas perante o conquistador espanhol. Não podemos negar o etnocídios e atrocidades cometidas contra os índios, mas devemos estar atentos também a uma imagem generalizada dos índios como agentes a-históricos, incapazes de resistir e questionar as relações de poder estabelecidas pelos espanhóis na América. Os relatos sobre a resistência indígena podem trazer outras perspectivas sobre as representações dos índios na história. Neste caminho indicamos a leitura do artigo "Colonialismo e idolatrias: cultura e resistência indígena no mundo colonial ibérico" de autoria do Ronaldo Vainfas (1991).

Para a abordagem do tema "guerras e expansão do império Inca", podemos ainda utilizar trechos que tratam dos episódios das origens e fundação do governo dos Incas sobre Andes, presente nas crônicas de Guaman Poma, Martin de Murúa e Sarmiento de Gamboa. Estas crônicas estão perpassadas também por questões relativas ao gênero e às identidades sociais no Andes. São reveladoras também de indícios significativos da presença feminina nas guerras, na política e na organização do governo dos Incas, ou seja, de mulheres exercendo o poder em uma das maiores organizações políticas que existiram na América Pré-hispânica. Essas histórias traduzem a possibilidade de que as mulheres estejam ligadas a projetos e ações que foram durante muito tempo considerados inacessíveis à elas. Trazendo para a sala de aula os indícios contidos nesta crônica podemos questionar as representações de gênero que demarcam papeis sociais com base na biologia, relegado a atuação das mulheres na história apenas ao espaço doméstico da maternidade e do casamento. Neste caminho, podemos capacitar os estudantes para que percebam também a historicidade das concepções e relações de gênero. Ao observar que os papeis sociais desempenhados pelas mulheres variam de uma cultura para outra, no tempo e no espaço. Deste modo, os estudantes passam a ter uma visão mais crítica das suas próprias concepções de gênero, bem como daquelas representações apresentadas como absolutas, universais e naturais sobre as relações de gênero e as possibilidades de 
atuação das mulheres em sociedade. Esta proposta pode contribuir no ensino de história para a igualdade de gênero e formação para cidadania.

\section{Considerações Finais}

Em suma, as crônicas aqui mencionadas permitem, em sala de aula, o desenvolvimento de debates e pesquisas sobre diversos temas: o imaginário espanhol sobre os índios, a construção das identidades e representações dos índios na história, as permanências e mudanças nas imagens dos índios na América, as condições de produção dos discursos sobre os índios e a América, as relações entre saber e poder, as culturas indígenas pré-hispânicas, os efeitos da conquista e colonização para as sociedades indígenas, os efeitos das representações veiculadas nas crônicas na construção das diferenças e desigualdades na América, as relações de poder e trabalho que os espanhóis estabeleceram com os indígenas, os diferentes papeis sociais e de gênero, os diferentes usos da terra, as relações com a natureza e a exploração colonial das terras americanas. Todos estes temas podem ainda ser evocados a partir de problemáticas do presente, como por exemplo: o reconhecimento da antiguidade e diversidade cultural indígena no continente americano, as heranças do colonialismo para as sociedades indígenas, a cidadania dos índios na América (incluindo o Brasil), as transformações e permanências históricas impostas pelas práticas de conquista/colonização européia da América, as lutas dos povos indígenas pelo direito à terra, e as relações étnico-raciais e de gênero na América.

A partir das propostas dos PCNs para o trabalho com eixos temáticos e documentos no ensino de história, traçamos aqui algumas sugestões para a abordagem das crônicas coloniais no ensino de história da América. No entanto, a definição das atividades e conteúdos desenvolvidos em sala de aula necessitam ser previamente pensados pelos/as professores/as com base também no currículo da escola e na observação das necessidades, interesses e conhecimento prévio de seus estudantes. 


\section{Crônicas Coloniais (Fontes)}

ACOSTA, Jose de [1590]. História natura y moral de las Indias. Disponível em:

<http://www.cervantesvirtual.com/servlet/SirveObras/0925273087468116 9643379/index.htm> Acesso em: 03 de fev. 2004.

BETANZOS, Juan de [1551]. Suma y Narración de los Incas. Madrid: Ediciones Atlas, 1987.

GARCILASO DE LA VEGA, El Inca [1609]. Comentarios Reales [1609]. In: Educar - Argentina, 1999. Disponível em: <http://www.educarargentina.com.ar/GARCILASO/comentario01.htm> Acesso em: 24 de jan. 2004.

. O Universo Incaico. Trad. de Rosângela Dantas. São Paulo: EDUC/Giordano/Loyola, 1992.

GUAMAN POMA DE AYALA, Felipe [1615/1616]. Nueva corónica y buen gobierno., México: Fondo de Cultura Económica, 1993. Tomo I. Disponível em:

<http://www.kb.dk/permalink/2006/poma/titlepage/es/text/?open=id3083 $608>$

LAS CASAS, Bartolomé Fray. Las antiguas gentes del Perú. Alicante:

Biblioteca Virtual Miguel de Cervantes, 2000. Disponível em:

<http://www.cervantesvirtual.com/servlet/SirveObras/0130508646613794

2200802/index.htm> Acesso em: 10 de fev. 2004.

- O Paraíso Destruído: a sangrenta história da conquista da América.

Porto Alegre: L\&PM, 2001.

MURÚA, Martín de [1590]. Historia del origen y genealogía real de los Reyes Incas del Perú. Madrid: Consejo Superior de Investigaciones Científicas, Instituto Santo Toribio de Mogrovejo, 1946.

SARMIENTO DE GAMBOA, Pedro [1572]. História de los Incas. Madrid: Miraguana Ediciones/Ediciones Polifemo, 1988.

\section{Referências}

BITTENCOURT, C. M. F. Ensino de história: fundamentos e métodos. 2. ed. São Paulo: Cortez, 2008. 
BRASIL. Secretaria de Educação Fundamental. Parâmetros curriculares nacionais: terceiro e quarto ciclos do ensino fundamental. história. Brasília: MEC/SEF, 1998.

CHARTIER, R. A história cultural: entre práticas e representações Lisboa: Difel, 1998.

FERNANDES, L. E.; MORAIS, M. V. Renovação da história da América. In: KARNAL, L. (Org.). História na sala de aula: conceitos, práticas e propostas. 2 ed. São Paulo: Contexto, 2004.

JODELET, D. (Org.). As Representações Sociais. Rio de Janeiro: Ed. Uerj, 2001.

JOVCHELOVITCH, S. Re(des)cobrindo o outro - para um entendimento da alteridade na teoria das representações sociais. In ARRUDA, A. (Org.) Representações da alteridade. Petrópolis, Rio de janeiro: Vozes, 1998.

LEÓN-PORTILLA, M. A conquista da América vista pelos índios: Relatos Astecas, Incas e maias. Petrópolis: Vozes, 1984.

MIGNOLO, W. "Cartas, crônicas y relaciones Del descubrimiento y la conquista" in: MADRIGAL, L. I. Historia de la Literatura Hispanoamericana.. 3. ed. Madrid: Cátedra, 1998. Tomo I: Época Colonial

NATALINO, E. dos S. As Tradições Históricas Indígenas diante da Conquista e Colonização da América: Transformações e Continuidades entre Nahuas e Incas. Revista de História, São Paulo, n. 150, jan./jun. 2004.

OLIVEIRA, S. R. de. As crônicas espanholas do século XVI e a produção de narrativas históricas sobre a América e seus habitantes. Revista Em tempo de Histórias, Brasília, v. 5, ano 5, 2002.

As crônicas coloniais e a produção de sentidos para o universo incaico e o passado das origens do Tawantinsuyo. Revista Dimensões. Dossiê: América, Américas. Vol. 19, Universidade Federal do Espírito Santos, 2008.

. Por uma história do possível: o feminino e o sagrado nos discursos dos cronistas e na historiografia sobre o "Império" Inca. 2006. 231 f. Tese (Doutorado em História) - Programa de Pós-Graduação em História da Universidade de Brasília, Brasília.

ORLANDI, E. P. Análise de Discurso: princípios e procedimentos. 5 ed. Campinas, SP: Pontes, 2003.

PEASE, F. G. Y. Las crónicas y los Andes. Lima: Pontificia Universidade Católica del Perú, 1995.

SCHMIDT, M. A.; CAINELLI, M. Ensinar história. São Paulo: Scipione, 2004. 
VAINFAS, Ronaldo. "Colonialismo e idolatrias: cultura e resistência indígenas no Mundo Colonial Ibérico". Revista Brasileira de História: América, Américas. São Paulo, v. 11, no. 21, set. 1990/fev. 1991.

ZAMBONI, E. Representações e linguagens no ensino de História. Revista Brasileira de História. vol. 18, n. 36, São Paulo, 1998. 